Nicola J. Giffin, MD

Richard B. Lipton, MD

Stephen D. Silberstein, MD

Jes Olesen, MD

Peter J. Goadsby, MD, $\mathrm{PhD}$

Correspondence to

Dr. Goadsby:

peter.goadsby@kcl.ac.uk

\section{The migraine postdrome}

\section{An electronic diary study \\ OPEN}

\section{ABSTRACT}

Objective: To report migraine postdrome symptoms in patients who report nonheadache symptoms as part of their attacks.

Methods: A prospective daily electronic diary study was conducted over 3 months in 120 patients with migraine. Nonheadache symptoms before, during, and after headache were collected on a daily basis. Visual analogue scales were used to capture the overall level of functioning and the severity of the headache. The postdrome was defined as the time from resolution of troublesome headache to return to normal.

Results: Of 120 evaluable patients, 97 (81\%) reported at least one nonheadache symptom in the postdrome. Postdrome symptoms, in order of frequency, included feeling tired/weary and having difficulty concentrating and stiff neck. Many patients also reported a mild residual head discomfort. In most attacks (93\%), there was return to normal within 24 hours after spontaneous pain resolved. There was no relationship between medication taken for the headache and the duration of the postdrome. The severity of the migraine was not associated with the duration of the postdrome. Overall state of health scores remained low during the postdrome.

Conclusion: Nonheadache symptoms in the postdrome were common and may contribute to the distress and disability in the patients studied. Postdrome symptoms merit larger observational studies and careful recording in clinical trials of acute and preventive migraine treatments.

Neurology ${ }^{\circledR}$ 2016;87:309-313

\section{GLOSSARY}

ICHD = International Classification of Headache Disorders.

Migraine is a common, disabling neurologic disorder characterized by a typically unilateral, often throbbing headache with associated features. The migraine attack is typically divided into 4 nonobligatory phases: the premonitory phase, the aura, the headache phase, and the postdrome. Nonheadache symptoms may start before the headache phase begins or during the premonitory period, ${ }^{1}$ the headache phase, or the postdrome. These symptoms involve brain activation of cortical and subcortical structures. ${ }^{2}$ Nonheadache symptoms may persist for 1 to 2 days after the headache has resolved in the postdrome or recovery phase. ${ }^{3}$ Postdromal symptoms, identified by retrospective recall of typical experiences, include tiredness, impaired concentration, and reduced mood. ${ }^{4}$

The postdrome, while disabling for many patients, ${ }^{3-6}$ has not been prospectively documented, and is not defined in the International Classification of Headache Disorders (ICHD). ${ }^{7}$ Electronic diaries, completed during and after migraine attacks, have many advantages for studying nonheadache symptoms. Contemporaneous diary reporting reduces recall bias. The electronic diary provides time-stamping so that investigators know when data were recorded. The purpose of this study is to characterize nonheadache symptoms in persons with migraine

From the Department of Neurology (N.J.G.), Royal United Hospital, Bath, UK; Albert Einstein College of Medicine (R.B.L.), New York, NY; Thomas Jefferson University (S.D.S.), Philadelphia, PA; Danish Headache Centre (J.O.), Glostrup Hospital, Denmark; NIHR-Wellcome Trust King's Clinical Research Facility (P.J.G.), King's College London, UK; and Department of Neurology (P.J.G.), University of California, San Francisco.

Go to Neurology.org for full disclosures. Funding information and disclosures deemed relevant by the authors, if any, are provided at the end of the article. The Article Processing Charge was paid by the authors.

This is an open access article distributed under the terms of the Creative Commons Attribution-NonCommercial-NoDerivatives License 4.0 (CC BY-NC-ND), which permits downloading and sharing the work provided it is properly cited. The work cannot be changed in any way or used commercially. 
reporting these. Descriptive data on postdromal features may shed light on their mechanisms and offer novel approaches to treating and terminating headaches.

METHODS Migraine patients $(\mathrm{n}=120)$ who claimed to experience nonheadache symptoms other than aura, nausea, vomiting, photophobia, and phonophobia preheadache, in at least 2 of 3 migraine attacks, were recruited from 4 centers and enrolled in a 3-month electronic diary study. The study was designed to detail nonheadache features in all phases of the migraine attack. The methods of this study have been previously described when the premonitory data were presented. ${ }^{1}$

Standard protocol approvals, registrations, and patient consents. The study was reviewed by each center's ethics board and patients gave written, informed consent.

Patients had between 2 and 8 migraines per month by the ICHD-1 criteria, which are similar to ICHD-3-beta criteria. ${ }^{7}$ Participants eligible for analyses had to record data from at least 3 headache attacks.

Definition. The postdrome was defined as the time between headache resolution and feeling completely back to normal. Headache resolution was defined as cessation of troublesome headache.

Diaries. The diaries were programmed to alarm randomly once daily during waking hours. Patients answered questions to capture nonheadache symptoms before, during, and after the migraine headache. Patients were encouraged to make voluntary entries when they experienced nonheadache symptoms or were experiencing a migraine attack. Diary entries could not be altered once confirmed by the participant.

Analysis. Data were tabulated and descriptive statistics were calculated using Excel (Microsoft, Redmond, WA). As an exploratory study, no power calculation was performed. Statistical testing was carried out using a level of significance of $p<0.05$ (SPSS 22; SPSS Inc., Chicago, IL).

RESULTS Of 120 recruited patients, 23 reported fewer than 3 migraines during the study period and were excluded from the analysis. Of the remaining 97 , there were 9 protocol violators: 1 did not usually experience 2-8 migraines per month, 5 recorded diary entries on fewer than $80 \%$ of days, and 3 took excluded medications: flunarizine or valproate. Twelve patients withdrew before the end of the study with diary fatigue, though all had usable data with more than 3 migraine headaches in the study period and were included in the analysis. A total of 352 diary entries during the postdrome were recorded: 160 recorded spontaneously by patients, 192 prompted by the electronic diary, and a further 421 afterwards. Data on a total of 773 migraine attacks with postdromes out of a total 873 migraine attacks from 97 patients were recorded.

Overall nonheadache symptoms in the postdrome before electronic diary use. Of the analyzed patients, 82 of 97 (85\%) patients estimated before using the electronic diary that they experienced nonheadache symptoms after the headache resolved. Of these 82 patients, $54(66 \%)$ estimated that they had nonheadache postdrome symptoms in more than $90 \%$ of their migraine attacks. The postdrome was estimated to linger for at least a day in $49 \%$ of patients (table 1).

Postdrome symptoms recorded in the electronic diary. Symptoms in the postdrome. We divided postdromal symptoms into 3 broad groups: cognitive/mood/energy, autonomic, and gastrointestinal symptoms, as well as sensory sensitivity. Being tired or weariness was the most common symptom, reported in $88 \%$ of postdromes. Other frequently reported symptoms included difficulty with concentration (56\%) and stiff neck (42\%). Typical migraine attack symptoms of nausea, photophobia, and phonophobia were also common (table 2). Mean quality of life score, as measured on a visual analogue rating score, was $57 / 100$, compared to 51 in the premonitory phase, 33 during the headache phase, and 81 between attacks.

Time to recovery in the postdrome. There was a return to normal within 6 hours of the end of the headache in 422 of 773 (54\%) migraine attacks with a postdrome; only $7 \%$ lasted more than 24 hours (table 3 ). Headache severity did not predict length of the postdrome $\left(F_{3,5}=3.2, p=0.25\right.$; table 3$)$.

Effect of medications. The duration of the postdrome did not vary significantly with the medication taken to relieve the migraine headache or headache severity $\left(F_{2,5}=6.8, p=0.08\right.$; table 3$)$.

Difference in the relative frequency of recalled and diary-based estimates of postdromal symptoms. In table 2 , we list the proportion of patients who report each postdrome symptom at baseline and compare it with the proportion who recorded those symptoms in the electronic diaries. There is a striking underestimation

\section{Table 1 Details of postdrome symptoms estimated by patients before using the electronic diary}

No. (\%)

After what proportion of migraine headaches does the patient experience nonheadache symptoms?

$>90 \%$ 54 (66)

$50 \%-90 \%$ 24 (29)

$30 \%-50 \%$

4 (5)

$<30 \%$

0 (0)

Total

NA

How long after the migraine headache has resolved do these symptoms resolve?

Immediately 2 (2)

After a few hours 40 (49)

$\geq 1$ day 40 (49)

Total $82(100)$

NA 15

Abbreviation: $\mathrm{NA}=$ not available. 
Table 2 Relative frequency of postdromal symptoms reported at baseline and recorded prospectively in the electronic diary study

\begin{tabular}{|c|c|c|}
\hline Nonheadache feature & $\begin{array}{l}\text { Percent of patients } \\
\text { who recalled each } \\
\text { postdromal symptom } \\
\text { at baseline ( } n=83 \text { ) }\end{array}$ & $\begin{array}{l}\text { prospectively } \\
\text { reporting each } \\
\text { postdromal symptom } \\
\text { during the e-diary } \\
\text { study }(\mathrm{n}=425 \text { ) }\end{array}$ \\
\hline Tired/weary & 75 & 88 \\
\hline Difficulty with concentration & 67 & 56 \\
\hline Stiff neck & 16 & 42 \\
\hline Light sensitive & 13 & 36 \\
\hline Intolerant/irritable & 22 & 29 \\
\hline Dizziness & 10 & 19 \\
\hline Yawning & 15 & 14 \\
\hline Pale face & 18 & 21 \\
\hline Noise sensitive & 12 & 32 \\
\hline Hunger/food craving & 15 & 15 \\
\hline Thirst & 13 & 32 \\
\hline Emotional & 13 & 24 \\
\hline Difficulty with thoughts & 15 & 33 \\
\hline Constipation & 4 & 7 \\
\hline Frequent urination & 7 & 21 \\
\hline Nausea/vomiting & 6 & 15 \\
\hline Difficulty reading or writing & 10 & 17 \\
\hline Difficulty with speech & 5 & 9 \\
\hline Other & 32 & 44 \\
\hline
\end{tabular}

of the frequency of neck stiffness and sensitivity to light and noise.

DISCUSSION We have shown in this study that postdrome symptoms are a frequent feature of migraine attacks in patients who report nonheadache symptoms, with more than $80 \%$ of attacks being followed by such symptoms. The data show that prevalence of these symptoms is underreported using recall at baseline relative to contemporaneous measurement using daily e-diaries. When identified, patients acknowledge the disabling nature of premonitory symptoms. Interestingly, the treatment type and attack severity did not seem to influence the duration of the postdrome. Data from this report, when combined with an earlier report from this cohort on the premonitory phase, ${ }^{1}$ reveals that some symptoms begin in the premonitory phase and extend through the postdrome. Given the reduced quality of life associated with these symptoms, and the importance of better understanding of attack termination, the postdrome deserves more systematic study.

Our data are in accordance with reported retrospective studies. In one study, 47 of 50 patients remained symptomatic after their headache had ended. ${ }^{4}$ In that study, the most frequent symptoms were changes in mood $(72 \%)$, muscular weakness
(54\%), and reduced appetite. In another study, 78 out of 100 unselected migraineurs reported resolution symptoms in a given attack ${ }^{5}$; most common were asthenia (55\%), tiredness (46\%), somnolence (29\%), and concentration difficulties (28\%). A large clinic-based sample found that 562 of 827 patients retrospectively reported postdromes; in $88 \%$, they lasted less than 24 hours. Tiredness was the most common symptom in $72 \% .{ }^{3}$ In a US study designed to test a postdrome instrument, patients $(\mathrm{n}=32)$ again reported tiredness, nausea, and concentration difficulties most commonly ${ }^{6}$

Most studies of postdromes have methodologic limitations. Retrospective studies are open to recall bias. The most recently experienced or severe postdromal symptoms may be selectively recalled and other features may be forgotten. Paper diaries may be retrospectively completed at times remote from the headache attack. In contrast, our study recorded the postdrome symptoms on a prospective basis, using a time-stamped electronic diary that could not be modified once data had been entered. Thus, we can be confident that features were recorded at the stated time, facilitating the assessment of individual attacks.

Characterization of postdromal nonheadache symptoms may lead us to a better understanding of the pathophysiology of the migraine process. Migraine pathophysiology involves dysfunction of diencephalic and brainstem centers thought to be involved in pain processing and other sensory modalities modulation. ${ }^{8}$ Pontine and midbrain structures have altered function during migraine attacks and after remissions that occur with triptans. Although triptans effectively treat migraine headache, they do not alter the fundamental brainstem mechanisms responsible for migraine generation. ${ }^{8}$ This may explain why although head pain is ameliorated by triptans, nonheadache symptoms persist.

There was little difference in postdrome duration between treated and untreated attacks. However, this was not a controlled study and no firm conclusion on the effect of medication on the postdrome can be reached. We did not analyze the time taken to recover in the postdrome after taking triptans compared to other medication. The effect of triptans on the postdrome has never been studied systematically and this is potentially an unexplored therapeutic area that would be of benefit to migraineurs.

Our study has several limitations. While we are confident that the symptoms were present during the postdromal phase, their background prevalence was not recorded, as we primarily recruited patients with premonitory symptoms. There are little data on the prevalence of interictal symptoms in migraineurs. Fatigue is reported in up to $70 \%$ of patients 


\begin{tabular}{|c|c|c|c|c|c|c|}
\hline Table 3 & \multirow{2}{*}{\multicolumn{6}{|c|}{$\begin{array}{l}\text { Return to normal in each time interval from end of migraine headache to } \\
\text { the end of the postdrome by medication taken to relieve migraine } \\
\text { headache or headache severity } \\
\text { Medication taken to relieve migraine headache, number of attacks (\%) }\end{array}$}} \\
\hline \multirow[b]{2}{*}{ Hours } & & & & & & \\
\hline & \multicolumn{3}{|c|}{ No $(n=199)$} & \multicolumn{2}{|c|}{ Yes $(n=574)$} & Total $(n=773)$ \\
\hline $0-2$ & \multicolumn{3}{|c|}{$49(25)$} & \multicolumn{2}{|c|}{$122(21)$} & $171(22)$ \\
\hline$>2-6$ & \multicolumn{3}{|c|}{78 (39) } & \multicolumn{2}{|c|}{$173(30)$} & 251 (32) \\
\hline$>6-12$ & \multicolumn{3}{|c|}{$35(18)$} & \multicolumn{2}{|c|}{$150(26)$} & $185(24)$ \\
\hline$>12-24$ & \multicolumn{3}{|c|}{$23(11)$} & \multicolumn{2}{|c|}{$90(16)$} & $113(15)$ \\
\hline$>24-48$ & \multicolumn{3}{|c|}{$12(6)$} & \multicolumn{2}{|c|}{$32(6)$} & $44(6)$ \\
\hline \multirow[t]{3}{*}{$>48$} & \multicolumn{3}{|c|}{$2(1)$} & \multicolumn{2}{|c|}{$7(1)$} & $9(1)$ \\
\hline & \multicolumn{6}{|c|}{ Severity of headache, number of attacks (\%) } \\
\hline & \multicolumn{2}{|c|}{ Mild $(n=150)$} & \multicolumn{2}{|l|}{ Moderate $(n=413)$} & Severe $(n=210)$ & Total $(n=773)$ \\
\hline $0-2$ & $33(22)$ & & $95(23)$ & & $43(21)$ & $171(22)$ \\
\hline$>2-6$ & $38(25)$ & & $146(35)$ & & $67(32)$ & 251 (32) \\
\hline$>6-12$ & 49 (33) & & $89(22)$ & & $47(22)$ & 185 (24) \\
\hline$>12-24$ & 23 (15) & & 54 (13) & & 36 (17) & $113(15)$ \\
\hline$>24-48$ & 7 (5) & & $24(6)$ & & $13(6)$ & $44(6)$ \\
\hline$>48$ & 0 & & 5 (1) & & 4 (2) & 9 (1) \\
\hline
\end{tabular}

with chronic headache ${ }^{9}$ and severe headache; sleep difficulty $(60 \%)$ and nausea/indigestion $(55 \%)$ are also common. ${ }^{10}$ We only studied patients selected from headache centers based on their nonheadache symptoms, limiting the generalizability of the conclusions. Population-based studies are needed to determine prevalence. Most symptoms were estimated reasonably accurately at baseline compared to those recorded in the diaries. We have not correlated the symptoms to medicine use, and conceivably some may be treatment effects. The underestimation of neck stiffness, light sensitivity, and noise sensitivity may occur because these symptoms are prominent during the headache phase and patients do not usually perceive them to be a problem after the headache.

The persistence of nonheadache symptoms throughout all phases of the migraine attack supports the hypothesis of persistent brain changes in the attack. An altered functional state may develop during the premonitory period and persist throughout the headache phase into the postdrome. The description of these symptoms opens the new challenge to pursue their biology and eventually better manage migraine.

\section{AUTHOR CONTRIBUTIONS}

Nicola Giffin: abstracted the data, drafted sections of the manuscript, and performed statistical analyses. Richard Lipton: helped design the study and analysis and drafted sections of the manuscript. Stephen Silberstein: helped design the study and reviewed the manuscript for intellectual content. Jes Olesen: helped design the study and reviewed the manuscript for intellectual content. Peter J. Goadsby: helped design the study and analysis, drafted and revised the manuscript for intellectual content.

\section{STUDY FUNDING}

Funded by GlaxoSmithKline. The King's CRF is funded by the NIHR and by the South London and the Maudsley Mental Health BRC. The views expressed are those of the authors and not necessarily those of the UK NHS, the NIHR, or the Department of Health, UK. The Article Processing Charge was paid by the authors.

\section{DISCLOSURE}

N. Giffin reports no disclosures relevant to the manuscript. R. Lipton receives research support from the NIH: PO1 AG003949 (Program Director), RO1AG025119 (Investigator), RO1AG022374-06A2 (Investigator), RO1AG034119 (Investigator), RO1AG12101 (Investigator), and the National Headache Foundation; serves on the editorial board of Neurology ${ }^{\circledR}$ and as senior advisor to Headache; has reviewed for the NIA and NINDS; holds stock options in eNeura Therapeutics; serves as consultant, advisory board member, or has received honoraria from Alder, Allergan, the American Headache Society, Autonomic Technologies, Avanir, Boston Scientific, Bristol Myers Squibb, Colucid, Dr. Reddy's, Electrocore, Eli Lilly, eNeura Therapeutics, Informa, Merck, Novartis, Pfizer, Teva, and Vedanta; and receives royalties from Wolfs S Headache, 8th edition, Oxford Press University, 2009. S. Silberstein: as a consultant and/or advisory panel member, Dr. Stephen Silberstein receives honoraria from Alder Biopharmaceuticals; Allergan, Inc.; Amgen; Avanir Pharmaceuticals, Inc.; Curelator, Inc.; Depomed; Dr. Reddy's Laboratories; eNeura Inc.; electroCore Medical, LLC; Lilly USA, LLC; Supernus Pharmaceuticals, Inc.; Teva Pharmaceuticals; and Trigemina, Inc. J. Olesen reports no disclosures relevant to the manuscript. P. Goadsby reports grants and personal fees from Allergan, grants and personal fees from eNeura Inc, personal fees from Autonomic Technologies Inc., grants and personal fees from Amgen Inc., personal fees from Alder Biopharmaceuticals, personal fees from Pfizer Inc., personal fees from Dr Reddy's Laboratories, personal fees from Zosano Pharma Corporation, personal fees from Colucid Pharmaceuticals, Ltd., personal fees from Eli Lilly and Company, personal fees from Avanir Pharmaceuticals, personal fees from WL Gore \& Associates, personal fees from Heptares Therapeutics, personal fees from Nupathe Inc., personal fees from Teva, personal fees from Cipla Ltd., personal fees from Ajinomoto Pharmaceuticals Co., personal fees from Akita Biomedical, personal fees from Wells Fargo, personal fees from Ethicon, US, personal fees from EMKinetics, personal fees from Promius Pharma, personal fees from Supernus, personal fees and other from Trigemina, personal fees from MedicoLegal work, personal fees from Journal Watch, and personal fees from Up-to-Date, outside the submitted work; and has a patent magnetic stimulation for headache pending, outside the submitted work. Go to Neurology.org for full disclosures.

Received September 11, 2015. Accepted in final form April 8, 2016.

\section{REFERENCES}

1. Giffin NJ, Ruggiero L, Lipton RB, et al. Premonitory symptoms in migraine: an electronic diary study. Neurology 2003; 60:935-940.

2. Maniyar FH, Sprenger $T$, Monteith $T$, Schankin $C$, Goadsby PJ. Brain activations in the premonitory phase of nitroglycerin triggered migraine attacks. Brain 2014; 137:232-242.

3. Kelman L. The postdrome of the acute migraine attack. Cephalalgia 2006;26:214-220.

4. Blau JN. Resolution of migraine attacks: sleep and the recovery phase. J Neurol Neurosurg Psychiatry 1982;45: 223-226.

5. Quintela E, Castillo J, Munoz P, Pascual J. Premonitory and resolution symptoms in migraine: a prospective study in 100 unselected patients. Cephalalgia 2006;26:10511060 .

6. Ng-Mak DS, Fitzgerald KA, Norquist JM, et al. Key concepts of migraine postdrome: a qualitative study to develop a post-migraine questionnaire. Headache 2011;51:105117. 
7. Headache Classification Committee of the International Headache Society. The International Classification of Headache Disorders, 3rd edition (beta version). Cephalalgia 2013;33:629-808.

8. Akerman S, Holland P, Goadsby PJ. Diencephalic and brainstem mechanisms in migraine. Nat Rev Neurosci 2011;12:570-584.
9. Spierings E, van Hoof M. Fatigue and sleep in chronic headache sufferers: an age- and sex-controlled questionnaire study. Headache 1997;37:549-552.

10. Maizels M, Burchette R. Somatic symptoms in headache patients: the influence of headache diagnosis, frequency, and comorbidity. Headache 2004;44:983993.

\section{Neurology ${ }^{\circledR}$ Online CME Program}

Earn CME while reading Neurology. This program is available only to online Neurology subscribers. Simply read the articles marked CME, go to Neurology.org, and click on CME. This will provide all of the information necessary to get started. The American Academy of Neurology (AAN) is accredited by the Accreditation Council for Continuing Medical Education (ACCME) to sponsor continuing medical education for physicians. Neurology is planned and produced in accordance with the ACCME Essentials. For more information, contact AAN Member Services at 800-879-1960.

\section{Save These Dates for AAN CME Opportunities!}

Mark these dates on your calendar for exciting continuing education conferences by the American Academy of Neurology.Learn more at AAN.com/conferences.

\section{Fall Conference}

- October 14-16, 2016, Las Vegas, NV, at the Cosmopolitan of Las Vegas

\section{Visit the Neurology ${ }^{\circledR}$ Resident \& Fellow Web Site}

Click on Residents \& Fellows tab at Neurology.org.

Now offering:

- Neurology ${ }^{\circledR}$ Resident \& Fellow Editorial team information

- "Search by subcategory" option

- E-pearl of the Week

- RSS Feeds

- Direct links to Continuum ${ }^{\circledR}$, Career Planning, and AAN Resident \& Fellow pages

- Recently published Resident \& Fellow articles

- Podcast descriptions

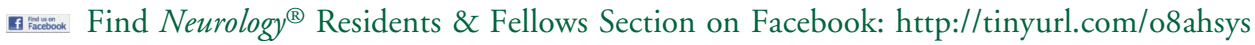

twitter Follow Neurology ${ }^{\circledR}$ on Twitter: http://twitter.com/GreenJournal 


\section{Neurology}

The migraine postdrome: An electronic diary study

Nicola J. Giffin, Richard B. Lipton, Stephen D. Silberstein, et al.

Neurology 2016;87;309-313 Published Online before print June 22, 2016

DOI 10.1212/WNL.0000000000002789

This information is current as of June 22, 2016

\section{Updated Information \&} Services

\section{References}

Citations

Subspecialty Collections

Permissions \& Licensing

Reprints including high resolution figures, can be found at: http://n.neurology.org/content/87/3/309.full

This article cites 10 articles, 2 of which you can access for free at: http://n.neurology.org/content/87/3/309.full\#ref-list-1

This article has been cited by 1 HighWire-hosted articles: http://n.neurology.org/content/87/3/309.full\#\#otherarticles

This article, along with others on similar topics, appears in the following collection(s):

All Clinical Neurology

http://n.neurology.org/cgi/collection/all_clinical_neurology Migraine

http://n.neurology.org/cgi/collection/migraine

Information about reproducing this article in parts (figures,tables) or in its entirety can be found online at:

http://www.neurology.org/about/about_the_journal\#permissions

Information about ordering reprints can be found online:

http://n.neurology.org/subscribers/advertise

Neurology ${ }^{\circledR}$ is the official journal of the American Academy of Neurology. Published continuously since 1951, it is now a weekly with 48 issues per year. Copyright () 2016 American Academy of Neurology. All rights reserved. Print ISSN: 0028-3878. Online ISSN: 1526-632X.

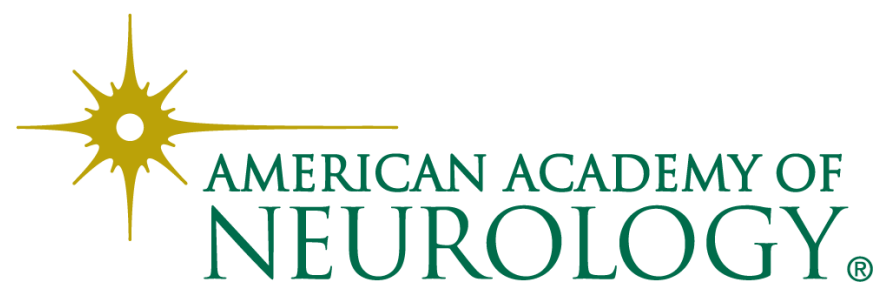

